\title{
Seletividade do Herbicida Fluazifop-p-butil para Cucurbitáceas ${ }^{1}$
}

\author{
Selectivity of the Herbicide Fluazifop-p-buthyl for Cucurbitaceae
}

VIDAL, R.A. ${ }^{2}$, KRUSE, N.D. ${ }^{3}$, FLECK, N.G. ${ }^{3}$ e MEROTTO JR., A. ${ }^{4}$

\begin{abstract}
RESUMO - Experimentos foram conduzidos em condições de casa de vegetação, com o objetivo de avaliar a seletividade do herbicida fluazifop-p-butil nas doses de 0, 94, 188, 376 e $752 \mathrm{~g}$ i.a. ha ${ }^{-1}$ para cinco espécies de cucurbitáceas (abobrinha, melancia, melão, moranga e pepino). Foi determinada a fitotoxicidade aos 14 dias após a aplicação dos tratamentos (DAT). Aos 20 DAT foram avaliadas a estatura, área foliar e matéria seca. O melão e o pepino mostraram sensibilidade ao fluazifop-p-butil na maior dose estudada, com maior intensidade no melão. Os resultados demonstraram que existe resposta a estes herbicidas mesmo dentro da classe Dicotiledoneae. Especula-se que essas respostas possam auxiliar no entendimento do completo mecanismo de ação desse herbicida.
\end{abstract}

Palavras-chave: herbicida, injúria, melão, pepino.

ABSTRACT - Experiments were conducted under greenhouse conditions to evaluate the selectivity of the herbicide fluazifop-p-buthyl at rates of $0,94,188$ and $752 \mathrm{~g}$ a.i. ha for five cucurbitaceous species (summer squash, watermelon, melon, pumpkin and cucumber). Plant injury at 14 days after treatments (DAT) and plant size, leaf area and dry weight at 20 DAT were determined. Melon and cucumber were susceptible to fluazifop-p-buthyl at the highest rate with highest herbicide effect being observed on melon. These results indicated that responses to these herbicides occur, even in the Dicotiledonae class. These responses are thought to help understand the overall mechanism of action of this herbicide.

Key words: herbicide, injury, melon, cucumber.

\section{INTRODUÇÃO}

Os herbicidas inibidores da acetil-CoA carboxilase (ACCase) são empregados como graminicidas pós-emergentes em diversas culturas dicotiledôneas, como soja, algodão, feijão, batata, fumo, entre outras. Dois grupos químicos reúnem os herbicidas com esse comportamento: ariloxifenoxipropionatos e ciclohexanodionas (Vidal, 1997).

Os dois grupos causam os mesmos sintomas de injúria sobre as gramíneas, sugerindo que eles possam ter um mecanismo de ação comum (Gronwald, 1991). O local-alvo da ação destes herbicidas nas gramíneas sensíveis é a ACCase, enzima que catalisa a carboxilação de acetil-CoA para formar malonil-CoA, sendo esta a reação inicial da síntese dos ácidos graxos e, em conseqüência, da síntese de lipídios (Gronwald, 1991; Ohlrogge \& Browse, 1995).

Há também a hipótese de que estes herbicidas poderiam ter uma ação biofísica (hipótese antiauxina), agindo no sentido de reduzir a diferença de potencial entre o interior e o exterior da célula, despolarizando a membrana e fazendo-a perder a seletividade. Especula-se

\footnotetext{
Recebido para publicação em 23/9/1999 e na forma revisada em 10/1/2000.

2 Engenheiro-Agrônomo, Ph.D., Professor Adjunto do Departamento de Plantas de Lavoura, Faculdade de Agronomia, UFRGS, Caixa Postal 776, 90001-970 Porto Alegre-RS, Brasil. Pesquisador do CNPq. <vidal@if1.ufrgs.br>; ${ }^{3}$ Engenheiro-Agrônomo, M.S., Prof. Assist. UFSM, aluno do Curso de Doutorado em Fitotecnia/UFRGS, bolsista da CAPES; ${ }^{4}$ Engenheiro-Agrônomo, M.S., Professor Assist. do Departamento de Plantas de Lavoura, Faculdade de Agronomia, UFRGS.
} 
também que este feito poderia decorrer da inibição na síntese de lipídios, que refletiria em menor capacidade de polarização da membrana (Wright \& Shimabukuro, 1987). Contudo, Di Tomaso (1994) questiona essa teoria, demonstrando, com Lolium rigidum resistente a diclofop, que a resposta da plasmalema a esses herbicidas provavelmente não esteja envolvida na fitotoxicidade provocada pelos inibidores da ACCase.

A grande seletividade desses herbicidas às espécies dicotiledôneas em geral encontra explicação no tipo e na compartimentalização dessa enzima na célula. Espécies gramíneas apresentam células apenas com uma forma de ACCase, tanto no citoplasma quanto no estroma dos cloroplastos. Já nas dicotiledôneas a forma presente no citoplasma seria equivalente à das gramíneas, enquanto a presente nos cloroplastos seria insensivel à ação desses herbicidas e responderia por toda síntese de lipídios quando a enzima citoplasmática estivesse inibida (Sasaki et al., 1995). Pela hipótese antiauxina, a seletividade se daria pela maior capacidade de repolarização da membrana das dicotiledôneas, quando na presença dos herbicidas (Holtum et al., 1991).

Mais recentemente, tem se especulado sobre a provável interação de vários herbicidas com a enzima $\mathrm{H}^{+}$-ATPase, a qual está presente nas membranas celulares, envolvida em muitas funções fisiológicas, principalmente agindo como bomba de prótons, permitindo assim a entrada de cátions e manutenção da diferença de $\mathrm{pH}$ entre o interior e o meio extracelular. Os herbicidas, entretanto, tiveram comportamento distinto na inibição desta enzima. Enquanto os ariloxifenoxipropionatos diclofop-metil, haloxyfop-metil, fenoxaprop-etil e quizalofopetil inibiram a ação da enzima em extratos (vesículas de membrana plasmática isoladas) de beterraba (Beta vulgaris cv. celt) e Alopecurus myosuroides, as cicloexanodionas cicloxydim e sethoxydim não inibiram a enzima $\mathrm{H}^{+}$-ATPase dos extratos de Alopecurus myosuroides, e apenas cicloxydim inibiu a $\mathrm{H}^{+}-$ ATPase dos extratos de beterraba (Hull \& Cobb, 1998). Segundo estes autores, a $\mathrm{H}^{+}$-ATPase da beterraba foi mais sensivel à inibição do que a enzima da gramínea Alopecurus myosuroides. Entretanto, se assim for, o papel dos herbicidas na inibição dessa enzima parece não estar, pelo menos diretamente, relacionado com sua ação graminicida.

A existência de espécies dicotiledôneas sensiveis aos herbicidas graminicidas representa problema acentuado para os produtores que se valem desses produtos para o controle de gramíneas, principalmente em culturas dicotiledôneas de elevado valor econômico. Desenvolveu-se o presente trabalho com o objetivo de avaliar a sensibilidade de culturas da família Cucurbitaceae aos herbicidas ariloxifenoxipropionatos.

\section{MATERIAL E MÉTODOS}

Os experimentos foram conduzidos em casa-de-vegetação, na Faculdade de Agronomia da UFRGS, em Porto Alegre, RS. Foram utilizadas cinco espécies da família Cucurbitaceae - abobrinha (Cucurbita pepo) cv. Menina Brasileira, melancia (Cirullus lanatus) cv. Charleston Gray, melão (Cucumis melo) cv. Amarelo Ouro, moranga (Cucumis maxima) cv. Abóbora Moranga exposição e pepino (Cucumis sativus) cv. Aodai - como reagente em cada experimento. Foram colocadas cinco sementes em vasos plásticos com capacidade de $500 \mathrm{~g}$ de solo, desbastando-se para duas plantas por vaso após concluída a emergência. Utilizaramse três repetições por tratamento, dispondoas pelo delineamento inteiramente casualizado. Sobre cada espécie, foram aplicadas cinco doses do herbicida fluazifop-p-butil, correspondendo a $0 ; 0,5 ; 1 ; 2$; e 4 vezes a dose recomendada para diversas culturas (188 $\left.\mathrm{g} \mathrm{ha}^{-1}\right)($ Rodrigues \& Almeida, 1995) . Os tratamentos herbicidas foram aspergidos 10 dias após a emergência das plantas, em condições climáticas do mês de março $\left(25{ }^{\circ} \mathrm{C}\right.$ de temperatura e $65 \%$ de umidade relativa), com aspersor costal pressurizado, pressão constante de $200 \mathrm{kPa}$, quatro bicos tipo leque 110.01 e volume de calda de $200 \mathrm{~L} \mathrm{ha}^{-1}$.

Aos 14 dias após a aplicação dos tratamentos (DAT), determinou-se a fitotoxicidade por avaliação visual, em que 0 representa a ausência de injúria e 100 a morte total das plantas. Aos 20 DAT avaliou-se a estatura das plantas (distância do solo até o nó do último par de folhas expandido), coletando-se então as plantas e determinando-se a área foliar e a matéria seca por planta. As variáveis estatura, área 
foliar e matéria seca foram submetidas à transformação logarítmica, e a variável fitotoxicidade, à transformação raiz quadrada de $\mathrm{x}+1,0$, sendo posteriormente submetidas à análise da variância pelo teste $\mathrm{F}$ e regressão, e as médias foram comparadas pelo teste DMS, a $5 \%$ de significância. A regressão foi empregada como desdobramento dos graus de liberdade de tratamentos, como regressão linear, quadrática e desvios da regressão.

\section{RESULTADOS E DISCUSSÃO}

Das cinco espécies estudadas, três apresentaram alta tolerância ao fluazifop-p-butil abobrinha, melancia e moranga (dados não apresentados) - e duas mostraram injúria melão e pepino - notadamente na maior dose empregada, de $752 \mathrm{~g} \mathrm{ha}^{-1}$. Analisando a toxicidade (Tabela 1), verifica-se que, no melão, a dose mais elevada provocou injúria de $67 \%$. No pepino, a fitotoxicidade foi de $33 \%$ para a dose mais elevada.

Tabela 1 - Médias de toxicidade de melão e pepino, sob aplicação do herbicida fluazifop-p-butyl. Fac.Agronomia/ UFRGS, Porto Alegre, RS, 1999

\begin{tabular}{|c|c|c|}
\hline Doses de & \multicolumn{2}{|c|}{ Fitotoxicidade $^{1}(\%)$} \\
\cline { 2 - 3 } fluazifop $\left(\mathrm{g} \mathrm{ha}^{-1}\right)^{2}$ & Melão & pepino \\
\hline 0 & $0,0 \mathrm{~b}$ & $0,0 \mathrm{~b}$ \\
94 & $0,0 \mathrm{~b}$ & $0,0 \mathrm{~b}$ \\
188 & $0,0 \mathrm{~b}$ & $0,0 \mathrm{~b}$ \\
376 & $0,0 \mathrm{~b}$ & $0,0 \mathrm{~b}$ \\
752 & $66,7 \mathrm{a}$ & $33,3 \mathrm{a}$ \\
\hline $\mathrm{CV}(\%)$ & 17,5 & 10,9 \\
\hline
\end{tabular}

' Avaliação visual percentual aos 14 dias após a aplicação dos tratamentos, em que 0 representa ausência de injúria e 100 a destruição completa da planta.

2 Fluazifop-p-butil na concentração de $125 \mathrm{~g} \mathrm{~L}^{-1}$.

- Valores seguidos de letras distintas diferem entre si $(\alpha=0,05$; teste DMS)

Nos demais indicadores avaliados, observando inicialmente a estatura (Figura 1), verifica-se que tanto para o melão como para o pepino o aumento da dose aplicada de fluazifop explica a redução de estatura observada, com regressão linear significativa e altos coeficientes de determinação encontrados, de 0,96 para melão e 0,95 para pepino.

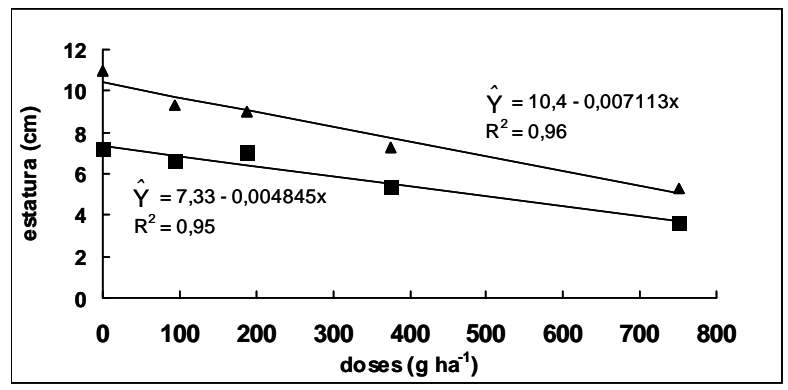

Figura 1 - Médias de estatura das cucurbitáceas melão $(\boldsymbol{\Delta})$ e pepino (ש) em resposta à aplicação de fluazifop-p-butil. Fac.Agronomia/UFRGS, Porto Alegre, RS, 1999.

A área foliar de melão descreve comportamento semelhante, em que o aumento da dose de fluazifop provoca decréscimo da área foliar nas duas espécies (Figura 2), com regressão linear significativa em ambas as culturas e coeficiente de determinação de 0,84 e 0,88 para melão e pepino, respectivamente.

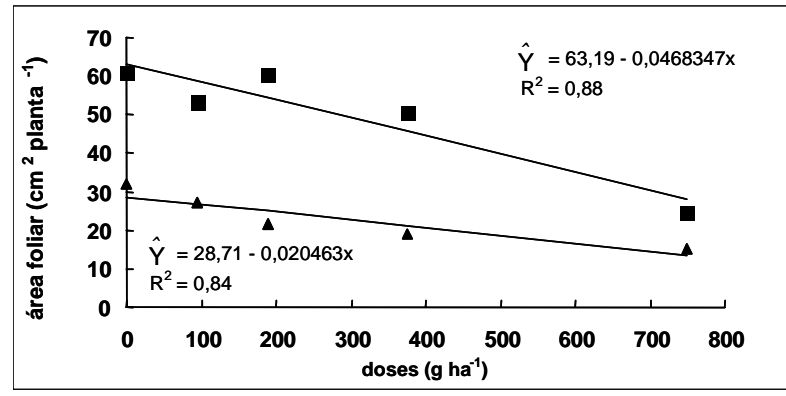

Figura 2 - Médias de área foliar das cucurbitáceas melão ( $(\mathbf{\Delta})$ e pepino (Ш) em resposta à aplicação de fluazifop-p-butil. Fac.Agronomia/UFRGS, Porto Alegre, RS, 1999.

O comportamento da matéria seca de melão e pepino em resposta à aplicação de fluazifop reflete o observado nos indicadores anteriores (Figura 3). No melão, a matéria seca das plantas que receberam a maior dose foi inferior à dos três primeiros tratamentos, não diferindo da obtida com aplicação de $376 \mathrm{~g} \mathrm{ha}^{-1}$. No pepino, a redução de matéria seca do tratamento com maior dose foi menos acentuada e o alto coeficiente de variação não permitiu significância na diferença com o tratamento 
sem fluazifop. Na Figura 3, isto fica confirmado, uma vez que se observa que no melão a redução de matéria seca é explicada pelo aumento na dose de fluazifop, com regressão significativa e coeficiente de determinação expressivo $(0,85)$. No pepino, obtiveram-se regressão não-significativa e baixo coeficiente de determinação, o que pode ser explicado pela injúria menos pronunciada que no melão, aliado ao alto coeficiente de variação (28\%) obtido para essa variável.

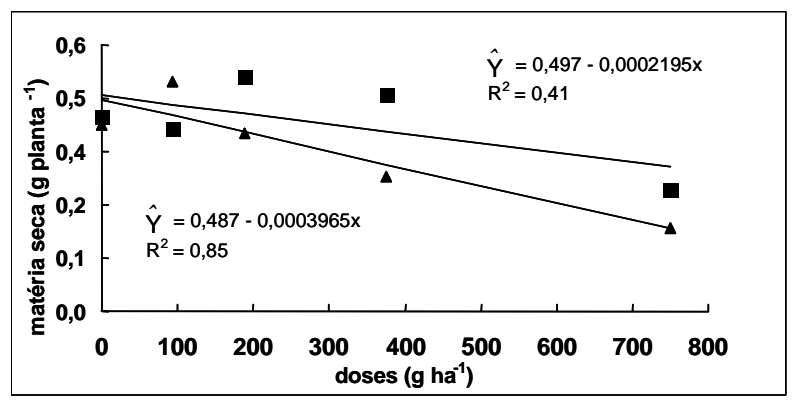

Figura 3 - Médias de matéria seca das cucurbitáceas melão (A) e pepino (ם) em resposta à aplicação de fluazifop-pbutil. Fac. Agronomia/UFRGS, Porto Alegre, RS, 1999.

Os resultados encontrados nos diferentes indicadores analisados permitem concluir que o melão e o pepino são suscetiveis ao fluazifop aplicado na dose de 376 e $752 \mathrm{~g} \mathrm{ha}^{-1}$. Ressaltase que as doses que provocaram injúria foram acima da dose recomendada para o controle de espécies sensiveis (duas e quatro vezes a dose recomendada), indicando a necessidade de verificar se há cultivares ou híbridos das referidas espécies que sejam sensíveis aos herbicidas. O tipo de injúria apresentada pelas cucurbitáceas não correspondeu ao observado em espécies gramíneas sensiveis, como descoloração próximo aos entrenós, folhas cloróticas e de coloração roxa, laranja ou vermelha (Vidal, 1997). As plantas de melão e pepino exibiram sintomas de manchas necróticas nas folhas, assemelhando-se aos herbicidas de ação tópica ou de contato, como os produzidos por inibidores de PROTOX, por exemplo. É interessante observar que a fórmula química estrutural dos herbicidas ariloxifenoxipropionatos e os difeniléteres assemelham-se bastante (Devine et al., 1993). Assim, especula-se que o fluazifop, em alta dosagem, poderia ter atuado como herbicida de ação tópica, de maneira análoga aos difeniléteres.

Outra possibilidade é de que o mecanismo de ação causador dos sintomas tenha sido a despolarização da membrana plasmática, em que as maiores doses superaram a capacidade de repolarização nestas espécies que exibiram o sintoma. Devine et al. (1993) verificaram que biótipo de aveia brava resistente aos inibidores de ACCase rapidamente restabelecia o potencial de membrana após a aplicação de diclofop e fenoxaprop, enquanto o biótipo suscetível permanecia despolarizado. Os autores concluíram que o efeito desses herbicidas sobre o potencial de membrana é componente importante de sua atividade herbicida. Portanto, os sintomas observados no melão e pepino poderiam advir deste tipo de atividade herbicida, já que estas espécies, por serem dicotiledôneas, possuem a forma da enzima ACCase (cloroplastos) insensivel ao fluazifop.

Com relação às diferenças encontradas entre melão e pepino, em que aparentemente os efeitos foram menos pronunciados no pepino, elas podem indicar que há variabilidade entre espécies de mesma família na sensibilidade a estes herbicidas. No pepino, os sintomas foram mais restritos à extremidade do limbo foliar, realçando o caráter de pouca mobilidade da elevada concentração do produto, com maior acúmulo nos bordos, por provável escorrimento da calda no momento da aspersão. Isto pode indicar maior dificuldade de absorção do produto no pepino, por características morfológicas, ou por maior capacidade do pepino em repolarizar a membrana em relação ao melão.

Os resultados sugerem que há sensibilidade de espécies dicotiledôneas aos herbicidas inibidores de ACCase, indicando a necessidade de que os extensionistas e agricultores sigam a bula dos produtos quanto às culturas e doses recomendadas.

\section{LITERATURA CITADA}

DEVIne, M., DUKE, S.O., FEDTKE, C. Physiology of herbicide action. Englewood Cliffs: PTR Prentice Hall, 1993. 441p. 
DEVINE, M.D., HALL, J.C., ROMANO, M.L. et al. Diclofop and fenoxaprop resistance in wild oat is associated with an altered effect on the plasma membrane electrogenic potencial. Pest. Biochem. Physiol., v.45, p.167-177, 1993.

DI TOMASO, J.M. Evidence against a direct membrane effect in the mechanism of action of graminicides. Weed Sci., v.42, n.2, p.302-309, 1994.

FRANS, R., CROWLEY, H. Experimental design and techniques for measuring and analyzing plant responses to weed control practices. In: SOUTHERN WEED SCIENCE SOCIETY. Research methods in weed science. 3.ed. Clemson: 1986. p.29-45.

GRONWALD, J.W. Lipid biosynthesis inhibitors. Weed Sci., v.39, n.3, p.435-449, 1991.

HOLTUM, J.A.M., HÄUSLER, R.E., DEVINE, M.D. et al. Recovery of transmembrane potentials in plants resistant to aryloxyphenoxypropanoate herbicides: a phenomenon awaiting explanation. Weed Sci., Champaign, v.42, n.3, p.293-301, 1991.
HULL, M.R., COBB, A.H. An investigation of herbicide interaction with the $\mathrm{H}^{+}$-ATPase activity of plant plasma membranes. Pest. Sci., v.53, n.2, p.155-164, 1998.

OHLROGGE, J., BROWSE, J. Lipid biosynthesis. Plant Cell, v.7, n.7, p.957-970, 1995.

RODRIGUES, B.N., ALMEIDA, F. Guia de herbicidas. 3.ed. Londrina: IAPAR, 1995. 675p.

SASAKI, Y., KONISHI, T., NAGANO, Y. The compartmentation of acetyl-coenzyme A carboxylase in plants. Plant Physiol., v.108, n.2, p.445-449, 1995.

VIDAL, R.A. Herbicidas: Mecanismos de ação e resistência de plantas. Porto Alegre: Pallotti, 1997. 165p.

WRIGHT, J.P., SHIMABUKURO, R.H. Effects of diclofop and diclofop-methyl on the membrane potencials of wheat and oat coleoptiles. Plant Physiol., v.85, n.1, p.188-193, 1987. 